\title{
Effects of cell wall deficiency in 'slime' strains of Neurospora crassa: a study on mycelial and wall-less phenotypic derivatives of a single $f z ; s g$; os-1 ('slime'-like) segregant
}

\author{
Rosemeire C. L. R. Pietro, JoÃo A. Jorge and Héctor F. Terenzi* \\ Departamento de Biologia, Faculdade de Filosofia, Ciências e Letras de Ribeirão Preto, Universidade de São Paulo, \\ 14049 Ribeirão Preto São Paulo, Brazil
}

(Received 13 June 1989; revised 9 September 1989; accepted 21 September 1989)

\begin{abstract}
Some morphological, physiological, enzymic and genetic characteristics of mycelial and plasmodioid phenotypes of Neurospora crassa, obtained by vegetative selection of a single $f z ; s g$; os-1 ('slime'-like) segregant of a cross 'slime' $x$ wild-type, were studied. The mycelial phenotype of the segregant, albeit altered in morphology, was otherwise fully normal for export and regulation of invertase and $\beta$-glucosidase. In contrast, both enzymes were oversecreted and were resistant to catabolic regulation in the stable 'slime' phenotype, derived from the same isolate. These results suggested that the enzymic defects of 'slime' appeared gradually, concomitantly with the loss of ability to construct a cell wall, as a consequence of the process of vegetative selection required to produce stable 'slime' from mycelium-forming 'slime'-like segregants. This idea was reinforced by the isolation of an intermediate phenotype, which exhibited mycelial/spheroplast dimorphism conditioned by the osmolarity of the culture medium. Crosses of the two extreme phenotypes of the $f z ; s g$; os- 1 segregant (the mycelial and the stable 'slime') failed to demonstrate any significant genetic difference between them.
\end{abstract}

\section{Introduction}

'Slime' strains of Neurospora crassa are defective in cell wall morphogenesis and grow as osmotically sensitive spheroplasts (Emerson, 1963). In addition to their characteristic cell wall deficiency, 'slime' strains oversecrete exoenzymes, including alkaline phosphatase (Burton \& Metzenberg, 1974), invertase (Bigger et al., 1972; Casanova et al., 1987; Pietro et al., 1989), alkaline protease and aryl- $\beta$-glucosidase (Pietro et al., 1989). Moreover, some of the carbon-regulated catabolic exoenzymes of 'slime' strains are resistant to glucose repression (Casanova et al., 1987; Pietro et al., 1989). The aforementioned defects are apparently inherent in the 'slime' wall-less phenotype, because they are not expressed in any of the mycelial phenotypes recovered from segregants of a cross of a 'slime'-containing heterokaryon and wild-type (Pietro et al., 1989).

The wall-less 'slime' phenotype is conditioned by three independently inherited genetic elements: $f z$ (fuzzy), $s g$ (spontaneous germination) and os- 1 (osmotic) (Emerson, 1963). The original 'slime' was obtained by mutagenic treatment, followed by selection in medium of high osmolarity, of an os- 1 strain, in which the other mutations, $f z$ and $s g$, were induced (Emerson, 1963).
Other 'slime' strains existent in stocks are derived from crosses of the original 'slime' (or its sibs) and wild-type strains, and all have been obtained by vegetative selection.

An intriguing observation is that ascospores carrying the $f z ; s g ; o s-1$ genotype, which germinate to produce a plasmodioid outgrowth ('slime'-like; Emerson, 1963), never maintain their original phenotype but develop an abnormal mycelium. Nevertheless, the mycelium produced by 'slime'-like segregants retains a tendency to release spheroplasts under high osmotic pressure (Emerson, 1963; Pietro et al., 1989). The stable 'slime' phenotype (i.e. the one which produces only spheroplasts, regardless of osmotic concentration) can sometimes be obtained by submitting the mycelium of 'slime'like segregants to a filtration-enrichment procedure of vegetative selection (Emerson, 1963; Nelson et al., 1975).

Until the present, little attention has been given to the mycelial phenotype of $f z$; $s g$;os- 1 strains, no doubt because the wall-less phenotype is a more attractive and unusual experimental system. Thus stable 'slime' strains have often been employed for isolation of subcellular organelles (Bigger et al., 1972; Martinoia et al., 1979) and of membranes (Scarborough, 1975), or for characteriza- 
tion of membrane-bound proteins including adenylate cyclase (Flawiá \& Torres, 1972; Terenzi et al., 1974), ATPase (Brooks et al., 1983) and a recently reported membrane-bound insulin-like receptor (Fawell \& Lenard, 1988). Other studies have investigated the enzymic basis of cell wall deficiency in 'slime' strains. According to these authors 'slime' is deficient in glucan synthase activity (Leal-Morales \& Ruiz Herrera, 1985) or in the subcellular organization of the components responsible for chitin synthesis, the chitosomes (Martinez et al., 1989). Nevertheless, if the process of vegetative selection, necessary for 'stabilizing' the wallless phenotype of 'slime', does not select for other mutations, as has been suggested (Pietro et al., 1989), it seems evident that $f z$; $s g$; os- $l$ mutants are in principle able to form a cell wall. Thus the irreversible loss of this structure, as well as other anomalies reported for stable 'slime' strains, may have been conditionally acquired as a result of environmental influences.

The aim of this study was to compare some physiological, genetic and biochemical characteristics of mycelial phenotypes and a stable 'slime' phenotype derived from a single 'slime'-like segregant, obtained from a cross of a 'slime'-containing heterokaryon and a wild-type strain.

\section{Methods}

Neurospora crassa strains and culture conditions. The following $N$. crassa strains were used: FGSC $424 a$ (wild-type); FGSC 810 (os-1;a); FGSC $2713(f z ; s g ;$ arg- $1 ;$ cr- $1 ;$ al-1; os $-1 ; A)+($ tol $;$ pan- $1 ; a)$ a 'slime'-containing heterokaryon; BAT 9-4 (cot-1; nic-3; $A)$ and BAT 9-5 (cot-1; nic-3;a), extra-fertile female parents (Cruz \& Terenzi, 1981) used for crosses. The first three strains were a gift from the Fungal Genetics Stock Center (Kansas City, Kansas, USA). Mycelial strains were propagated on slants of solid Vogel's (1964) medium supplemented with $2 \%(\mathrm{w} / \mathrm{v})$ sucrose and auxotrophy supplements, when required. 'Slime' strains were maintained by weekly transfers on slants of solid Vogel's medium supplemented with $2 \%$ glucose, $0.75 \%$ bactopeptone (Difco) and $0.75 \%$ yeast extract (Difco) (complete medium). Liquid cultures were prepared in $250 \mathrm{ml}$ Erlenmeyer flasks containing $50 \mathrm{ml}$ Vogel's minimal or complete medium supplemented with $2 \%$ glucose. Otherwise, medium composition is indicated for each experiment. The inoculum consisted of suspensions of macroconidia $\left(5 \times 10^{5} \mathrm{ml}^{-1}\right)$, or mycelial fragments for non-conidiating strains, or of 'slime' spheroplasts, collected by suspending in $0.25 \mathrm{M}$-sorbitol the growth of a slant not more than $3 \mathrm{~d}$ old.

Cultures were incubated with agitation (100 r.p.m.) at $30^{\circ} \mathrm{C}$ for $48 \mathrm{~h}$, then harvested by filtration (mycelial strains) or centrifugation at $159 \mathrm{~g}$ for $15 \mathrm{~min}$ ('slime' strains). The resulting samples were either transferred to fresh medium as indicated for each experiment, or processed for enzyme assay, in which case both the culture filtrates and supernatants were saved.

Enzyme assays. Invertase and $\beta$-glucosidase activities were assayed as previously described (Pietro et al., 1989). Specific activities (intracellular and extracellular) are expressed as units per mg protein of crude cell extracts. Protein was determined by the Lowry method, using bovine serum albumin (Sigma) as standard.

Crosses. Crosses were performed according to standard procedures (Davis \& de Serres, 1970), using strains BAT 9-4 $(A)$ or BAT 9-5 $(a)$ as female parents, in Petri dishes supplemented with solid Westergaard \& Mitchell (1947) crossing medium. Segregants were isolated from plates of minimal Vogel's medium supplemented with $50 \mu \mathrm{g}$ nicotinic acid, $100 \mu \mathrm{g}$ arginine, $1 \%(\mathrm{w} / \mathrm{v})$ sorbose, $0.1 \%$ glucose, $0.1 \%$ fructose and 1 M-sorbitol. 'Slime'-like segregants (Emerson, 1963) were submitted to a filtration-enrichment protocol essentially as described by Nelson et al. (1975). Other details of the process of vegetative selection of mycelial and plasmodioid phenotypes are given in Results.

Photographs were taken using a Zeiss photomicroscope using AGFA COPEX PAN-AHU film.

Chemicals. $p$-Nitrophenyl $\beta$-D-glucoside, cellobiose, raffinose, sorbitol, cycloheximide and sorbose were from Sigma. All other chemicals were of the best quality available.

\section{Results}

Vegetative selection of two mycelial and a stable plasmodioid phenotype from a single ascospore carrying the $f z ; s g$; os- 1 genotype

Five segregants of a cross FGSC $2713 \times$ BAT 9-5, showing small plasmodioid outgrowth at germination ('slime'-like), were selected and individually transferred to $50 \mathrm{ml}$ Erlenmeyer flasks containing $10 \mathrm{ml}$ of liquid medium C (Nelson et al., 1975). The cultures were incubated at $30^{\circ} \mathrm{C}$ with agitation (100 r.p.m.). The isolates grew slowly, initially forming a compact colony still attached to the piece of agar. After about $7 \mathrm{~d}$, free mycelial fragments and a variable number of spheroplasts appeared in the liquid medium. Samples of mycelial fragments were isolated and subcultured in solid medium of normal osmolarity with the auxotrophic supplements of the parents of the cross. These mycelial isolates, designated 'mycelial intermediate', had the typical appearance described by Emerson (1963), i.e. very poor growth habit, reduced aerial hyphae, parenchymatous surface mycelium with blobs of exudate and a brown-yellowish (buff) pigmentation. After isolation of mycelial fragments, the liquid cultures were filtered through glass wool, one-third of the original volume of fresh liquid medium $\mathrm{C}$ was added, and the cultures were reincubated as before. This procedure was repeated every $2 \mathrm{~d}$ until only spheroplasts were observed in the culture. One isolate, RCP-3, reached this stage after about $30 \mathrm{~d}$ of continuous selection. The plasmodioid growth habit of isolate RCP-3 was stable in solid or liquid medium of high osmolarity, while in media of normal osmolarity reversion to hyphal morphology occurred. Selection applied to the other four isolates seemed fruitless and was discontinued at this time. Then a further selection step was applied to isolate RCP-3, 
Table 1. Morphology of the phenotypes derived from the 'slime'-like segregant $R C P-3$ in different media

Cultures were made on plates of solid medium; morphology was observed after $36 \mathrm{~h}$ incubation at $30^{\circ} \mathrm{C}$.

\begin{tabular}{|c|c|c|c|}
\hline \multirow[b]{2}{*}{ Culture conditions } & \multicolumn{3}{|c|}{ Morphological phenotype } \\
\hline & Mycelial intermediate & $\begin{array}{c}\text { Spheroplast- } \\
\text { hyphal } \\
\text { intermediate }\end{array}$ & $\begin{array}{l}\text { Stable } \\
\text { 'slime' }\end{array}$ \\
\hline Minimal Vogel's medium & Mycelium & Mycelium & $\begin{array}{l}\text { Plasmodioid } \\
\text { growth }\end{array}$ \\
\hline $\begin{array}{l}\text { Minimal Vogel's medium } \\
+1.0 \mathrm{M} \text {-sorbitol }\end{array}$ & $\begin{array}{l}\text { Mycelium with plasmodioid } \\
\text { outgrowth at the borders }\end{array}$ & $\begin{array}{l}\text { Plasmodioid } \\
\text { growth }\end{array}$ & $\begin{array}{l}\text { Plasmodioid } \\
\text { growth }\end{array}$ \\
\hline Complete Vogel's medium & Mycelium & Mycelium & $\begin{array}{l}\text { Plasmodioid } \\
\text { growth }\end{array}$ \\
\hline $\begin{array}{l}\text { Complete Vogel's medium } \\
+1.0 \mathrm{M} \text {-sorbitol }\end{array}$ & $\begin{array}{l}\text { Mycelium with plasmodioid } \\
\text { outgrowth at the borders }\end{array}$ & $\begin{array}{l}\text { Plasmodioid } \\
\text { growth }\end{array}$ & $\begin{array}{l}\text { Plasmodioid } \\
\text { growth }\end{array}$ \\
\hline
\end{tabular}

beginning by culturing it in complete liquid medium containing $1.0 \mathrm{M}$-sorbitol. Filtration-enrichment selection was continued until mycelial growth was no longer observed. At this stage, the sorbitol concentration was lowered to $0.8 \mathrm{M}$, and selection was continued. By repeating this procedure and gradually decreasing the sorbitol concentration it was possible to obtain a culture actively growing as a homogeneous spheroplast population in the absence of sorbitol. This stable 'slime' of segregant RCP-3 was morphologically identical to other 'slime' strains maintained in our laboratory e.g. FGSC 1118.

During the course of vegetative selection, other cellwall-forming isolates were recovered from myceliumforming colonies scattered on a background of 'slime' growth, in plates of complete solid medium without sorbitol. In medium of normal osmolarity these isolates exhibited a mycelial growth habit somewhat resembling that of the mycelial intermediate, but with much sparse, wet and fragile surface growth and a complete absence of aerial hyphae. Under high osmolarity, however, only spheroplasts were produced. Because of its properties this phenotype of segregant RCP-3 was designated 'spheroplast-hyphal intermediate'.

Table 1 summarizes the main morphological characteristics of the three pheonotypes derived from the 'slime'-like segregant RCP-3. All of them proved to be quite stable: they have maintained their characteristics up to the present time after being repeatedly subcultured on slants of minimal (mycelial and spheroplast-hyphal intermediates) and complete (stable 'slime') Vogel's medium without sorbitol.
Growth and morphology of the spheroplast-hyphal intermediate in liquid medium without sorbitol

The predominant morphology of the spheroplast-hyphal intermediate in liquid medium without sorbitol, at the end of the growth phase, consisted of short $(200-400 \mu \mathrm{M})$, thin unbranched hyphae. The hyphal tube emerged from spherical or arthrospore-like structures (Fig. 1a). When samples of these cells were transferred to fresh medium, the hyphae became thicker and swelled into bulges around the septa (Fig. 1b; Fig. 2c). At the same time, small buds appeared along the hyphae; these eventually detached as spherical cells (Fig. 1b, Fig. 2a). The extremities of the hyphae showed a tendency to fragment, releasing arthrospore-like structures (Fig. $2 d)$. Even in young growing cultures, cell wall ghosts appeared (Fig. 2b,d). The hyphae formed by the spheroplast-hyphal intermediate were evidently rather fragile and had a tendency to burst, releasing their cytoplasmic contents. Because of this characteristic, these cells were handled by centrifugation rather than by filtration.

\section{Effect of sorbitol on growth and morphology of the spheroplast-hyphal intermediate}

In sorbitol-supplemented medium the spheroplasthyphal intermediate formed exclusively spheroplasts (Fig. 2e). These cells were still able to develop hyphae in the absence of sorbitol when transferred to minimal, but not to complete medium.

The effect of sorbitol concentration on morphology 


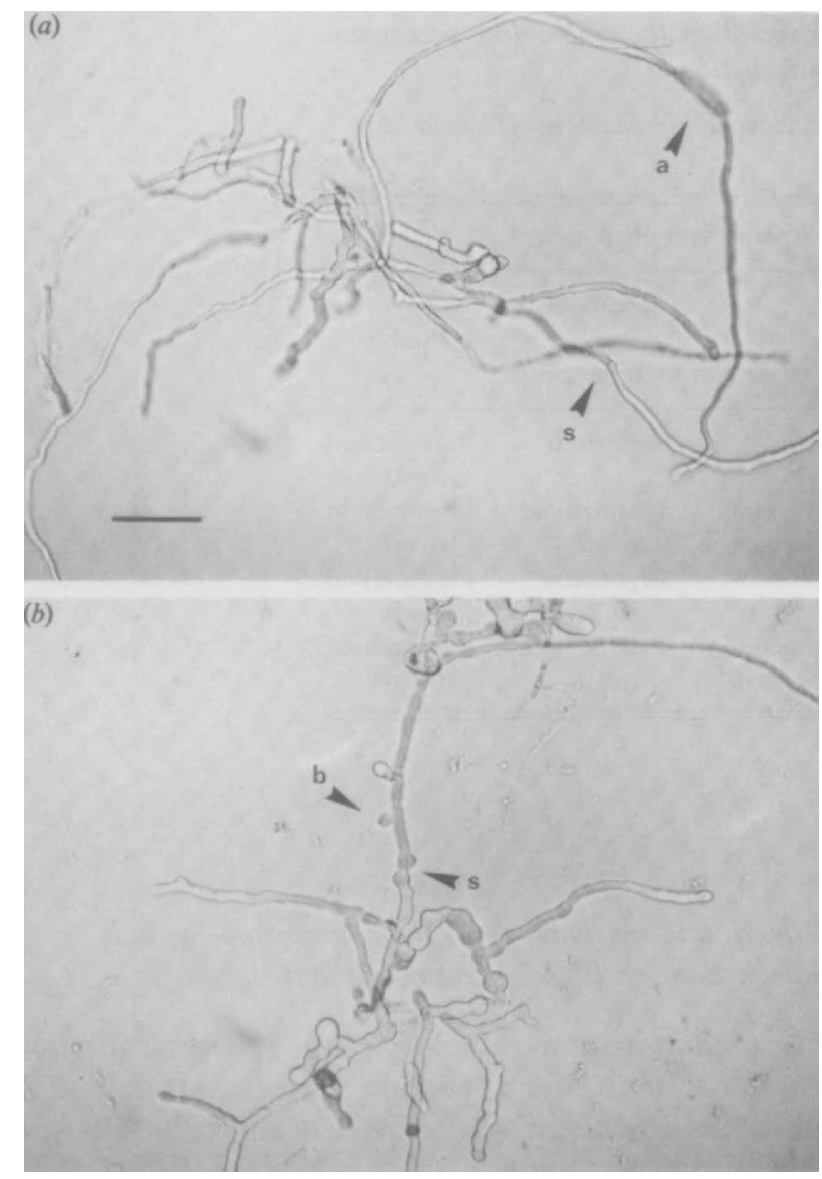

Fig. 1. (a) Morphology of the spheroplast-hyphal intermediate of segregant RCP-3 after $\mathbf{4 8} \mathrm{h}$ growth in Vogel's complete liquid medium without sorbitol. (b) Cells of the same culture $6 \mathrm{~h}$ after transfer to fresh medium of the same composition. a, arthrospore-like structure with microhyphae; b, bud; s, hyphal septum. Bar, $50 \mu \mathrm{m}$.

and growth of the spheroplast-hyphal intermediate, the stable 'slime' and the mycelial intermediate of the 'slime'-like segregant RCP-3 was investigated (Fig. 3). For comparative purposes a wild-type and an osmotic (os-1) strain were also included. Sorbitol inhibited growth of the os-1 mutant. High $(0 \cdot 6-1 \cdot 0 \mathrm{M})$ sorbitol concentrations affected the mycelial morphology of the $o s-1$ mutant, its hyphae becoming swollen and contorted (not shown). However, formation of spheroplasts was not observed. Growth of the mycelial intermediate of segregant RCP-3 was also sensitive to high sorbitol concentrations (Fig. 3). Some spheroplasts were produced in the presence of $1.0 \mathrm{M}$-sorbitol, but the culture mass was predominantly mycelial $(99 \%$ of total cell protein). Sorbitol had negligible effects on the growth of the spheroplast-hyphal intermediate (Fig. 3), but its effects on cell morphology were striking (compare Fig.
$1 a$ with Fig. $2 e$ ). In the presence of sorbitol at each concentration tested $(0 \cdot 2-1 \cdot 0 \mathrm{M})$, the spheroplast-hyphal intermediate produced only spheroplasts. Sorbitol concentration affected the size of the spheroplasts, which were larger (30-40 $\mu \mathrm{m}$ diameter) and vacuolated in $0.2 \mathrm{M}$ sorbitol, and smaller ( $15 \mu \mathrm{m}$ diameter) and devoid of an observable vacuole in $0.8-1.0 \mathrm{M}$-sorbitol.

The stable 'slime' strain developed as a homogeneous spheroplast population in either the presence or absence of sorbitol. The size of these cells was also affected by sorbitol concentration, spheroplasts appearing smaller and without large vacuoles at higher concentrations. Interestingly, sorbitol did not inhibit, but considerably stimulated, growth of the stable 'slime' (Fig. 3).

Effect of cycloheximide on the morphology of sorbitolinduced spheroplasts of the spheroplast-hyphal intermediate

As mentioned in the preceding section, sorbitol-induced spheroplasts of the spheroplast-hyphal intermediate recovered the ability to continue cell wall synthesis in the absence of sorbitol, when transferred to minimal, but not to complete medium. However, continuous cultivation of these cells in the presence of sorbitol resulted in the irreversible loss of their capacity to form cell walls, thus originating the stable 'slime'. This observation suggested that cultivation in the presence of high osmolyte concentration not only inhibited cell wall formation, but also caused progressive loss, or inactivation, of critical (surface-located?) elements required for cell wall morphogenesis. A possible explanation is that the sorbitolinduced spheroplasts of the spheroplast-hyphal intermediate were not able to regenerate cell wall in rich medium, because their capacity for cell wall morphogenesis was too low to keep pace with the rate of cell mass increase under those conditions. In that case, partial growth inhibition might restore the ability to regenerate cell wall in these cells. We tested this possibility by using the antibiotic cycloheximide, which inhibits the synthesis of proteins more severely than that of polysaccharides and other cell wall constituents (Liras \& Gascon, 1971; Farkas et al., 1970). Cycloheximide concentrations which inhibited cell growth to $35-60 \%$ of the control (Fig. 4) induced cell wall regeneration in spheroplasts of the spheroplast-hyphal intermediate cultured in complete medium of normal osmolarity, while in the absence of the antibiotic these spheroplasts proliferated as such without forming hyphae. Identical treatment failed to induce cell wall formation by spheroplasts of the stable 'slime' strain, thus confirming that the ability of these cells to form cell wall was irreversibly lost. 

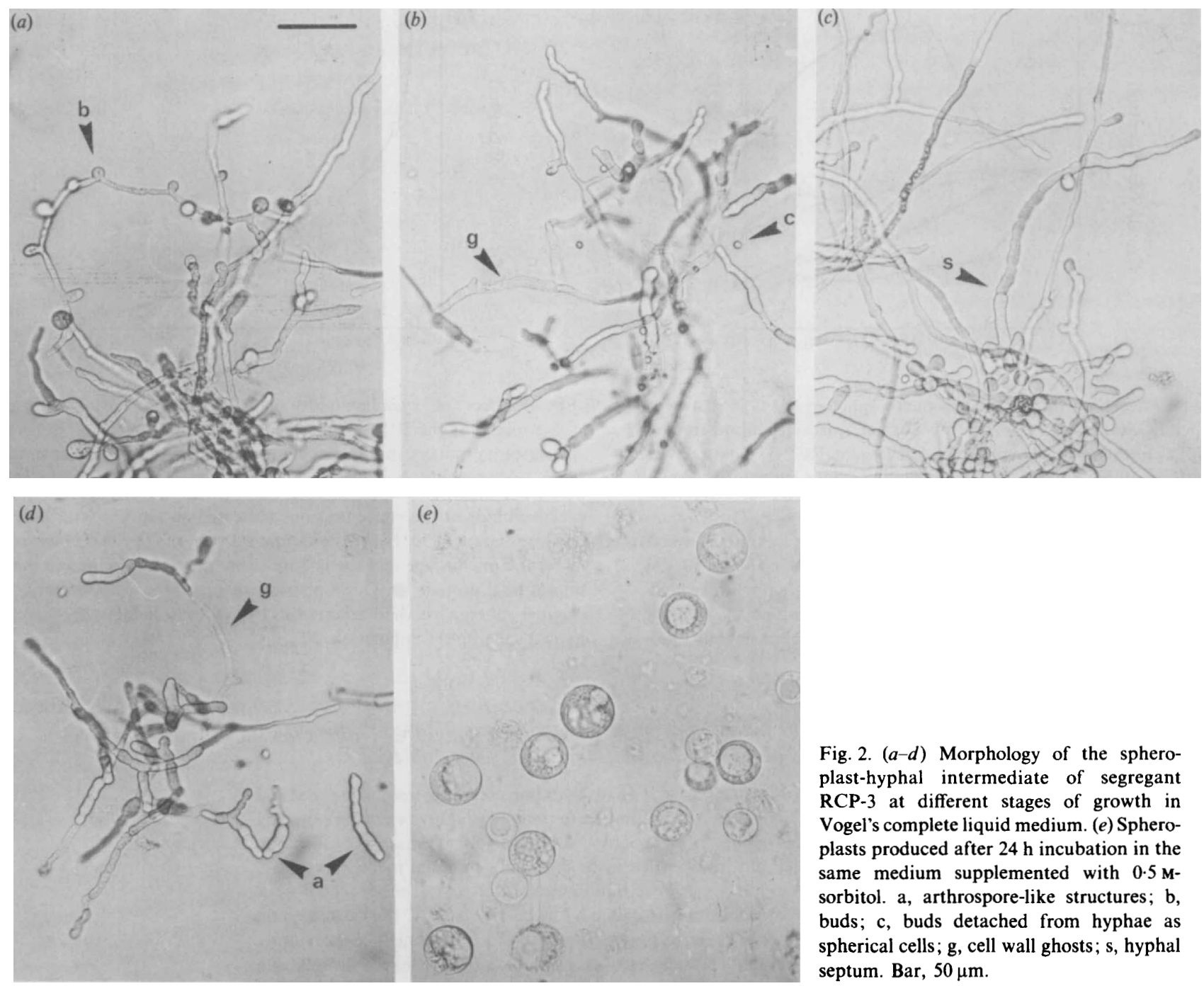

Fig. 2. (a-d) Morphology of the spheroplast-hyphal intermediate of segregant RCP-3 at different stages of growth in Vogel's complete liquid medium. (e) Spheroplasts produced after $24 \mathrm{~h}$ incubation in the same medium supplemented with $0.5 \mathrm{M}$ sorbitol. a, arthrospore-like structures; b, buds; c, buds detached from hyphae as spherical cells; $g$, cell wall ghosts; $\mathbf{s}$, hyphal septum. Bar, $50 \mu \mathrm{m}$.

Comparison of the different phenotypes of the 'slime'-like segregant RCP-3 on the basis of enzyme markers which differentiate stable 'slimes' from the wild-type

Together with the irreversible loss of cell wall, stable 'slimes' show an abnormally high secretion and defective regulation of several exoenzymes (see Introduction). Would such enzyme defects be also present in the cellwall-forming phenotypes of 'slime'? This question prompted us to examine, in the two mycelial and the plasmodioid phenotypes derived from the 'slime'-like segregant RCP-3, two of the enzyme markers characteristically defective in 'slime': invertase and $\beta$-glucosidase. The results (Table 2) demonstrated that the characteristic enzyme defects of 'slime' strains arose during the process of vegetative selection of stable 'slime' from the mycelial 'slime'-like segregant. This conclusion was drawn from the following observations (Table 2).
(1). The spheroplast-hyphal intermediate (with hyphal morphology) and the stable 'slime' derived from segregant RCP-3 hypersecreted invertase and $\beta$-glucosidase. The extracellular level of these enzymes relative to total activity varied from $77 \%$ to $96 \%$ for i1 vertase, and from $33 \%$ to $66 \%$ for $\beta$-glucosidase (not considering the values at zero time, which corresponded to cultures incubated for $48 \mathrm{~h}$ ). In contrast, the mycelial intermediate showed extracellular levels of invertase and $\beta$-glucosidase $(26 \%$ and $8 \%$ respectively) comparable to those reported for wild-type and for segregants with mycelial phenotype of a cross of 'slime' and wild-type (Pietro et al., 1989).

(2) The mycelial intermediate of segregant RCP-3 was also normal in terms of carbon source regulation for the two enzymes studied. For instance, galactose-induced invertase and cellobiose-induced $\beta$-glucosidase activities were 18-fold higher than those of the respective glucose-incubated cultures. Moreover, glucose repression 


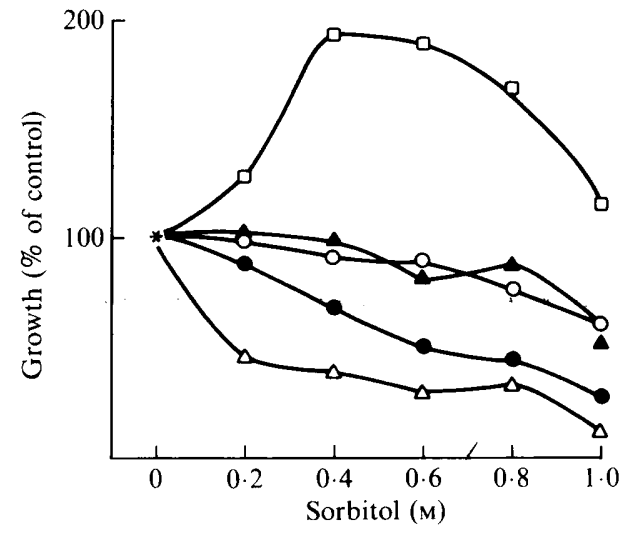

Fig. 3. Effect of sorbitol on growth and morphology of FGSC 424 (wildtype), FGSC $810(o s-1)$, and the mycelial intermediate and spheroplasthyphal intermediate phenotypes of segregant RCP-3. Cultures were made in $10 \mathrm{ml}$ Vogel's complete liquid medium supplemented with sorbitol at the concentrations indicated on the abscissa. They were incubated at $30^{\circ} \mathrm{C}$, with agitation ( 100 r.p.m.), for 48 h. Growth was estimated on the basis of total protein; $\mathrm{mg}$ total protein of the cultures at zero time (*) was FGSC 424, 57.1 mg; FGSC 810, $64 \cdot 3 \mathrm{mg}$; RCP-3 mycelial intermediate $10.6 \mathrm{mg}$; RCP-3 spheroplast-hyphal intermediate, $27 \cdot 1 \mathrm{mg}$; RCP-3 stable 'slime', $23 \cdot 1 \mathrm{mg}$. O, Wild-type; os- $1 ; \triangle$, RCP-3 mycelial intermediate; $\boldsymbol{\Delta}, \mathbf{R C P}-3$ spheroplast-hyphal intermediate; $\square$, RCP-3 stable 'slime'.

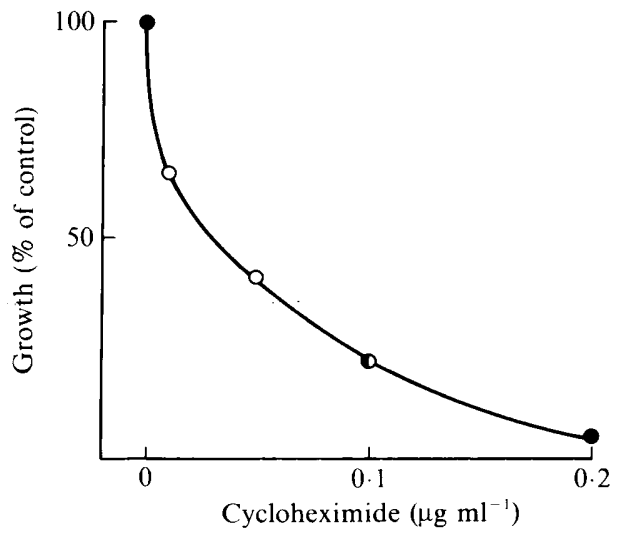

Fig. 4. Effect of cycloheximide on growth and morphology of spheroplasts of the RCP-3 spheroplast-hyphal intermediate. Spheroplasts were produced in Vogel's complete liquid medium supplemented with $0.6 \mathrm{M}$-sorbitol. Samples $(0.5 \mathrm{ml})$ were inoculated into $10 \mathrm{ml}$ of medium of the same composition, but without sorbitol, containing cycloheximide at the concentrations indicated on the abscissa. After $20 \mathrm{~h}$ incubation at $30^{\circ} \mathrm{C}$ with agitation, cell morphology was observed under the microscope and the cultures were processed for determination of total protein. Only spheroplasts present in the culture; $\bigcirc$, original spheroplasts had reverted to hyphal morphology; $\mathbf{D}$, mixed hyphal/spheroplast population.

Table 2. Specific activities of invertase and $\beta$-glucosidase in different phenotypes obtained from the 'slime'-like segregant RCP-3

All strains were grown for $48 \mathrm{~h}$ at $30^{\circ} \mathrm{C}$ with agitation, in Vogel's complete medium supplemented with $2 \%$ glucose. At that time (zero time) the cultures were harvested by centrifugation (stable 'slime' and spheroplast-hyphal intermediate) or filtration (mycelial intermediate) and resuspended in fresh Vogel's minimal medium with $2 \%$ glucose, $0.2 \%$ cellobiose, $1.35 \%$ galactose, or mixtures of glucose and either cellobiose or galactose at the same concentrations. After $6 \mathrm{~h}$ incubation at $30^{\circ} \mathrm{C}$ the cultures were harvested and invertase or $\beta$-glucosidase activities were determined in the culture medium and cell extracts as indicated in Methods. Intracellular ('Intra') and extracellular ('Extra') specific activities are expressed as units per mg of crude extracted protein. All experiments were repeated at least three times. Representative results are shown. ND, Not detected.

\begin{tabular}{|c|c|c|c|c|c|c|}
\hline \multirow[b]{3}{*}{ Conditions } & \multicolumn{6}{|c|}{ Morphological phenotype } \\
\hline & \multicolumn{2}{|c|}{$\begin{array}{c}\text { Mycelial } \\
\text { intermediate }\end{array}$} & \multicolumn{2}{|c|}{$\begin{array}{l}\text { Spheroplast-hyphal } \\
\text { intermediate }\end{array}$} & \multicolumn{2}{|c|}{ Stable 'slime' } \\
\hline & Intra & Extra & Intra & Extra & Intra & Extra \\
\hline \multicolumn{7}{|l|}{ (a) Invertase } \\
\hline Zero time & $2 \cdot 2$ & $0 \cdot 7$ & $24 \cdot 3$ & $347 \cdot 1$ & $3 \cdot 1$ & $177 \cdot 05$ \\
\hline Glucose & 1.5 & $0 \cdot 1$ & $8 \cdot 2$ & $29 \cdot 3$ & $7 \cdot 2$ & $74 \cdot 9$ \\
\hline Galactose & $22 \cdot 4$ & $8 \cdot 0$ & $47 \cdot 6$ & $151 \cdot 7$ & $3 \cdot 45$ & $78 \cdot 35$ \\
\hline $\begin{array}{l}\text { Galactose } \\
+ \text { glucose }\end{array}$ & $6 \cdot 4$ & ND & $22 \cdot 8$ & $78 \cdot 65$ & $7 \cdot 0$ & $127 \cdot 1$ \\
\hline \multicolumn{7}{|c|}{ (b) $\beta$-Glucosidase } \\
\hline Zero time & $7 \cdot 5$ & 1.8 & $36 \cdot 3$ & $157 \cdot 5$ & $8 \cdot 15$ & $240 \cdot 6$ \\
\hline Glucose & $3 \cdot 2$ & $0 \cdot 3$ & $12 \cdot 7$ & $24 \cdot 5$ & $10 \cdot 65$ & $8 \cdot 5$ \\
\hline Cellobiose & $57 \cdot 3$ & $3 \cdot 9$ & $119 \cdot 1$ & $59 \cdot 5$ & $16 \cdot 5$ & $29 \cdot 6$ \\
\hline $\begin{array}{l}\text { Cellobiose } \\
+ \text { glucose }\end{array}$ & $4 \cdot 4$ & $0 \cdot 4$ & $23 \cdot 2$ & $22 \cdot 1$ & $17 \cdot 9$ & $15 \cdot 2$ \\
\hline
\end{tabular}


strongly affected invertase and $\beta$-glucosidase production when cultures were incubated with a mixture of both glucose and inducer substrate. In that case, the activities of invertase and $\beta$-glucosidase decreased to $21 \%$ and $7.8 \%$ respectively, of the activity of cultures incubated with the inducer only.

(3) For the spheroplast-hyphal intermediate (with mycelial morphology), the inductive effect of galactose and cellobiose increased invertase and $\beta$-glucosidase activities only $5 \cdot 3$-fold and $4 \cdot 8$-fold, respectively. When glucose was present together with the inducer, invertase activity was $51 \%$ and $\beta$-glucosidase activity was $25 \%$ of that of the cultures incubated with the inducer carbon source only. Thus, in comparison with the mycelial intermediate, the spheroplast-hyphal intermediate showed a relaxed control of synthesis and secretion of both invertase and $\beta$-glucosidase.

(4) The stable 'slime' produced invertase constitutively. Neither the inductive effect of galactose nor the repressive effect of glucose affected the synthesis of this enzyme. For example: total invertase activity of the spheroplast-hyphal intermediate cultures, incubated with galactose, was more than twice that of the corresponding stable 'slime' cultures, while for glucoseincubated cultures invertase activity showed just the opposite behaviour. For $\beta$-glucosidase activity a small but significant inductive effect of cellobiose was observed in the stable 'slime', which affected mostly the extracellular activity, represented by aryl- $\beta$-glucosidase (Pietro et al., 1989). In this case the repressive effect of glucose was very small, again affecting the extracellular $\beta$-glucosidase more. These results obtained with the stable 'slime' from segregant RCP-3 were fully consistent with previous ones, obtained with other stable 'slime' strains (Pietro et al., 1989).

\section{Genetic analysis of the mycelial intermediate and the stable 'slime' of segregant RCP-3}

The two extreme phenotypes derived from segregant RCP-3, i.e. the mycelial intermediate and the stable 'slime', were crossed with BAT 9-4 $(A)$ and BAT 9-5 (a) as protoperithecial parents. These experiments focused on the question of whether there were genetic differences between the two phenotypes. Perithecia were produced in BAT 9-4 $A$ crosses indicating that RCP-3 was of the $a$ mating type. Mature perithecia and ascospores were more abundant for the cross of the mycelial intermediate than for the cross of stable 'slime'. Random spores, submitted or not to heat activation, were plated on medium supplemented with $1 \%$ sorbose and $1.0 \mathrm{M}-$ sorbitol. Germination was scored under a dissecting microscope after overnight incubation at $30^{\circ} \mathrm{C}$. For the cross of the mycelial intermediate, germination was $90.5 \%$ and $56.1 \%$, respectively, for spores which had or had not been submitted to heat activation, while for crosses of the stable 'slime' these figures were $63.1 \%$ and $35 \%$. These results demonstrated the segregation of the $s g$ (spontaneous germination) mutation (Emerson, 1963). Simultaneously, germlings with a plasmodioid outgrowth, tentatively classified as 'slime'-like $(f z ; s g ; o s-I)$ (Emerson, 1963) were scored. For the mycelial intermediate cross these segregants represented $10.97 \%$ $(138 / 1258)$ and for that of the stable 'slime' $11.44 \%$ $(65 / 568)$. None of these segregants maintained its original plasmodioid phenotype, forming mycelial colonies after 1 or $2 \mathrm{~d}$. Although the presumptive genotype of these segregants was not definitively established on a genetic basis, these results demonstrated beyond doubt that the inheritance of plasmodioid phenotypes was not improved by the process of vegetative selection which originated the stable 'slime' from segregant RCP-3. Visual observation also permitted the recognition, in both crosses, of the occurrence of abortive germination and other growth anomalies already described by Emerson (1963).

After a further $48 \mathrm{~h}$ incubation, 120 colonies of the mycelial intermediate cross and 103 colonies of the stable 'slime' cross were isolated from plates seeded with heatactivated spores. These segregants were subcultured on slants of Vogel's medium at $30^{\circ} \mathrm{C}$ and after $7 \mathrm{~d}$ were examined and classified on the basis of the two other morphological traits directly related to the 'slime' phenotype: $f z$ (fuzzy) and os-1 (osmotic). Osmotic was scored on a morphological basis only. $f z$ and os- 1 segregated independently: $44 \%$ os -1 and $48 \% f z$ for the mycelial intermediate cross, and $53 \%$ os -1 and $60 \% f z$ for that of stable 'slime'. Segregation of the other markers present in the parents of the cross, unrelated to the 'slime' phenotype, was observed but not recorded. On the whole, these results lead us to conclude that segregant RCP-3 had the genotype $f z$; sg;os- 1 ; al -1 and that its two phenotypic variants, mycelial and stable 'slime', were seemingly identical from a genetic standpoint.

\section{Discussion}

In a previous study (Pietro et al., 1989) we suggested that some phenotypic deficiencies of 'slime' strains, such as inability to perform cell wall synthesis, or hypersecretion and loose catabolic control of carbon-related exoenzymes, were epigenetic in nature. Specifically, such deficiencies would arise progressively during the process of vegetative selection which was necessary for obtaining stable 'slimes' from mycelial 'slime'-like segregants. A corollary of this hypothesis was that no new mutation, 
different from those essential for the stable 'slime' phenotype (and already present in 'slime'-like segregants) had been selected during the process of vegetative propagation under high osmotic pressure. The evidence presented in this study appears to reinforce this view, as discussed below.

(1) Segregant RCP-3 was initially scored because of its tendency to produce a plasmodioid outgrowth on germination, presumptive of the existence of the mutations $f z ; s g$;os -1 ; this was later confirmed by genetic experiments. Despite its rather poor mycelial growth habit, lack of conidiation and some tendency to release spheroplasts when cultured under conditions of high osmolarity, the mycelial intermediate of the 'slime'like segregant RCP-3 was otherwise normal as regards export and regulation of invertase and $\beta$-glucosidase. In addition, the mycelial intermediate exhibited the typical sensitivity of other $o s-1$ mutants to environments of high osmolarity.

(2) Selective pressure was applied to the 'slime'-like segregant RCP-3 in order to obtain a stable 'slime' phenotype. This selection was based on two main environmental conditions: presence of sorbose, which interferes with the synthesis of cell wall constituents (Quigley \& Selitrennikoff, 1984), and presence of sorbitol at a concentration which greatly increases the osmotic pressure of the medium and inhibits growth of $o s-1$ mutants. The inhibition mechanism by which sorbitol or other osmolytes affects growth of osmotic mutants is not clear, but it might be mediated through interaction with cell wall components. Observe, for instance, that growth of the two other phenotypes derived from the 'slime'-like segregant, namely the spheroplast-hyphal intermediate and the stable 'slime', appeared not to be sensitive to sorbitol inhibition (Fig. 3), although it is possible that sorbitol inhibition was masked by a protective effect of this substance on the growth of these osmotically fragile cells.

Continuous propagation in the presence of sorbose and sorbitol induced a permanent change in the morphology of the 'slime'-like segregant, originating a fully stable derivative which produced exclusively spheroplasts under normal culture conditions. At this stage 'slime' became highly stable and practically never reverted to a mycelial phenotype. Concomitantly with the morphological transformation, stable 'slime' hypersecreted exportable proteins. In this respect, 'slime' strains seemed analogous to the so-called fragile mutants (srb-1) of Saccharomyces cerevisiae (Waltschewa et al., 1989), which also hypersecrete exoenzymes and are defective in cell wall composition. More interestingly, the stable 'slime' phenotype was radically altered in carbon-related control of at least two exportable proteins: invertase and $\beta$-glucosidase. It should be added that loss of carbon catabolite control in 'slime' has been also reported for one non-exportable catabolic enzyme: cellobiase (Pietro et al., 1989). Genetic experiments failed to demonstrate significant differences in the pattern of segregation of markers in crosses made with the mycelial intermediate as compared with the stable 'slime' obtained from segregant RCP-3. For instance, improved inheritance of 'slime'-like or new morphological phenotypes among segregants of the cross of the stable 'slime' in comparison with that of the mycelial intermediate was not observed. This evidence reinforces the idea of the epigenetic nature of the mycelial/spheroplast transformation of RCP-3 segregant.

(3) The properties of the spheroplast-hyphal intermediate suggested that the mycelial/spheroplast morphological transformation of segregant RCP-3 occurred gradually. The spheroplast-hyphal intermediate exhibited a dimorphic growth habit conditioned by the osmolarity of the medium, but this was not observed for the mycelial intermediate. Even in the absence of osmoticum, the spheroplast-hyphal intermediate was incapable of extensive mycelial growth, forming thin, short and rather fragile hyphae which grew not by branching, but apparently by budding and arthrosporelike fragmentation at the extremities (Figs 1 and 2). On the other hand, other morphological characteristics of $N$. crassa hyphae, such as the septum, were observed. In addition to its morphological alterations, the spheroplast-hyphal intermediate of segregant RCP-3, in its hyphal form, showed weakened control of synthesis and export of invertase and $\beta$-glucosidase.

In principle, we conclude that the spheroplast-hyphal intermediate of segregant RCP-3 had a somewhat reduced ability to form cell wall, in comparison with the mycelial intermediate. It has been suggested (Kang \& Cabib, 1986) that in fungi cell wall morphogenesis must be coupled to other anabolic processes which occur during the cell cycle. In that case such coupling may be absent in 'slime', because the organism when proliferating rapidly does not construct a cell wall envelope. When protein synthesis was inhibited with cycloheximide (Fig. 4) with a consequent reduction in cell growth rate, sorbitol-induced spheroplasts of the spheroplast-hyphal intermediate were able to regenerate cell wall under culture conditions (rich medium) which otherwise would unbalance cell wall synthesis and growth, leading to the formation of wall-less spheroplasts.

In conclusion, it is clear that the mechanism by which $f z ; s g$;os- 1 mutants irreversibly lose the ability to continue cell wall synthesis and to regulate carbon-related catabolic enzymes deserves a thorough examination at the molecular level. Among other very interesting questions are those related to glucan synthase activity, reportedly inactive in stable 'slimes' 
(Leal-Morales \& Ruiz-Herrera, 1985) but perhaps active in mycelial phenotypes. Analogous questions may be posed on the problem of chitin synthase activity (Martinez et al., 1989). No less interesting would be a study of the changes in cell wall structure and composition which must occur during the vegetative conversion of mycelial phenotypes into stable 'slimes' when submitted to selective pressure and, obviously, the characterization of the putative elements eventually associated with the cell surface which mediate recognition of environmental signals.

This work forms part of a thesis submitted by R.C.L.R.P. to the Department of Biochemistry of the School of Medicine of Ribeirão Preto, University of São Paulo, in partial fulfilment of the requirement for the doctoral degree.

This work was supported by grants from Financiadora de Estudos e Projetos (FINEP-PADCT) no. 44-84.0820-00, Fundação de Amparo à Pesquisa do Estado de São Paulo (FAPESP) no. 87/0139-2, and Conselho Nacional de Pesquisas (CNPq) no. 405-713/88.6. R.C.L. R.P. received a graduate (Doctoral) fellowship from Coordenadoria de Aperfeiçoamento de Pessoal de Ensino Superior (CAPESBRASIL). We are indebted to Drs Maurilio R. Alves and Catarina $S$. Takahashi for help with photomicrographs.

\section{References}

Bigger, C. H., White, M. R. \& BRAYMeR, H. D. (1972). Ultrastructure and invertase secretion of the slime mutant of Neurospora crassa. Journal of General Microbiology 71, 159-166.

Brooks, K. M., AdDison, R. \& SCARborough, G. A. (1983). Isolation and characterization of plasma membranes from strains of Neurospora crassa with wild type morphology. Journal of Biological Chemistry 258, 13909-13918.

Burton, E. G. \& METZEnBerg, R. L. (1974). Properties of repressible alkaline phosphatase from wild type and a wall-less mutant of Neurospora crassa. Journal of Biological Chemistry 249, 4679-4688.

Casanova, A., Martinez, J. P., Gil, M. L., Sentandreu, R. \& RuizHerrera, J. (1987). Different molecular forms of invertase in the slime variant of Neurospora crassa: comparison with the wild-type strain. Journal of General Microbiology 133, 2447-2456.

Cruz, A. K. \& TerenzI, H. F. (1981). Derepression of tyrosinase by sexual stimulation. Neurospora Newsletter 28, 8-10.

DAVIS, R. H. \& DE SERRES, F. J. (1970). Genetic and microbiological research techniques for Neurospora crassa. Methods in Enzymology 17A, 79-143.
EMERSON, S. (1963). 'Slime'. A plasmodioid variant of Neurospora crassa. Genetica 34, 162-182.

Farkas, V., Svoboda, A. \& Bauer, S. (1970). Secretion of cell-wall glycoproteins by yeast protoplasts. Effect of 2-deoxy-D-glucose and cycloheximide. Biochemical Journal 118, 755-758.

FAWELL, S. E. \& LeNARD, J. (1988). A specific insulin receptor and tyrosine kinase activity in the membranes of Neurospora crassa. Biochemical and Biophysical Research Communications 155, 59-65.

Flawí, M. M. \& TORRES, H. N. (1972). Adenylate cyclase activity in Neurospora crassa. I. General properties. Journal of Biological Chemistry 247, 6873-6879.

KANG, M. S. \& CABIB, E. (1986). Regulation of fungal cell wall growth: a guanine nucleotide-binding, proteinaceous component required for activity of $(1 \rightarrow 3) \beta$-D-glucan synthase. Proceedings of the National Academy of Sciences of the United States of America 83, 5808-5812.

Leal-Morales, C. A. \& Ruiz-Herrera, J. (1985). Alterations in the biosynthesis of chitin and glucan in the slime mutant of Neurospora crassa. Experimental Mycology 9, 28-38.

LiRas, P. \& GaSCON, S. (1971). Biosynthesis and secretion of yeast invertase. Effect of cycloheximide and 2-deoxy-D-glucose. European Journal of Biochemistry 23, 160-165.

Martinez, J. P., Giménez, G. \& Bartnicki-Garcia, S. (1989). Sedimentation properties of chitosomal chitin synthetase from the wild type strain and the 'slime' variant of Neurospora crassa. Biochimica et Biophysica Acta 990, 45-52.

Martinoia, E., Heck, U., Boller, Th., Wiemken, A. \& Matile, Ph. (1979). Some properties of vacuoles isolated from Neurospora crassa slime variant. Archives of Microbiology 120, 31-34.

Nelson, R. E., Littlewood, B. S. \& Metzenberg, R. L. (1975). Toward the domestication of slime. Neurospora Newsletter 22, 15-16.

Pietro, R. C. L. R., Jorge, J. A. \& Terenzi, H. F. (1989). Pleiotropic deficiency in the control of carbon-regulated catabolic enzymes in the 'slime' variant of Neurospora crassa. Journal of General Microbiology 135, 1375-1382.

Quigley, D. R. \& SelitrennikofF, C. P. (1984). $\beta(1 \rightarrow 3)$-Glucan synthase activity of Neurospora crassa: kinetic analysis of negative effectors. Experimental Mycology 8, 320-333.

SCARBorough, G. A. (1975). Isolation and characterization of Neurospora crassa plasma membranes. Journal of Biological Chemistry 250, 1106-1111.

Terenzi, H. F., Flawiá, M. M. \& Torres, H. N. (1974). A Neurospora crassa morphological mutant showing reduced adenylate cyclase activity. Biochemical and Biophysical Research Communications 58, 990-996.

VOGEL, H. J. (1964). Distribution of lysine pathways among fungi: evolutionary implications. American Naturalist 98, 435-446.

Waltschewa, L., Philipova, D. \& Verikov, P. (1989). Increased extracellular secretion in fragile mutants of Saccharomyces cerevisiae. Yeast 5, S313-S320.

Westergaard, M. \& Mitchell, H. K. (1947). Neurospora V. A synthetic medium favoring sexual reproduction. American Journal of Botany 34, 573-577. 